\title{
ADOLESCÊNCIA E LAÇO SOCIAL: UMA LEITURA PSICANALÍTICA SOBRE O USO DO FACEBOOK
}

\author{
Adolescence and Social Bond: A Psychoanalytic Reading on the Use of Facebook
}

Adolescencia y Lazo Social: Una Lectura Psicoanalítica sobre el Uso del Facebook

Adolescence et Lien social : Une Lecture Psychanalytique sur l'Utilisation de Facebook

doi) $10.5020 / 23590777 . r s . v 20 i E s p 2 . e 9498$

\author{
Lívia de Matos Lima \\ Psicóloga, Mestranda em Psicanálise e Cultura na Universidade Federal de Uberlândia (UFU).
}

\section{Tiago Humberto Rodrigues Rocha}

Psicólogo, Psicanalista, Doutor com dupla titulação em Psicologia Social (USP-SP) e pela Université de Rennes 2 (França). Professor e Coordenador do Curso de Psicologia da Universidade Federal do Triângulo Mineiro.

\begin{abstract}
Resumo
O presente artigo é decorrente de uma pesquisa que objetivou analisar a relação entre o uso do Facebook e o estabelecimento do laço social entre adolescentes. Participaram da pesquisa 10 adolescentes, que foram entrevistados, e tomou-se a psicanálise como principal referencial teórico. A partir da análise dos dados, foi possível perceber que a imagem ocupou lugar privilegiado nos enlaçamentos, uma vez que os adolescentes buscam reconhecimento social através de mecanismos do Facebook, valorizando aspectos quantitativos em detrimento dos aspectos qualitativos nas relações. Um dos principais efeitos observados foi o enfraquecimento das produções simbólicas, subjetivas e singulares. Assim, o trabalho atua como ponto de partida para futuras discussões em prol da análise das vicissitudes contemporâneas sobre o laço social estabelecido por adolescentes.
\end{abstract}

Palavras-chave: psicanálise; adolescência; laço social; contemporaneidade; Facebook.

Abstract

This article is the result of a research that aimed to analyze the relationship between the use of Facebook and the establishment of social bonds among adolescents. Ten adolescents participated in the research, they were interviewed, and psychoanalysis was taken as the main theoretical framework. From the analysis of the data, it was possible to perceive that the image occupied a privileged place in the relationships, since adolescents seek social recognition through Facebook mechanisms, valuing quantitative aspects in detriment of the qualitative aspects in relationships. One of the main effects observed was the weakening of symbolic, subjective, and singular productions. Thus, the work acts as a starting point for future discussions in favor of the analysis of contemporary vicissitudes on the social bond established by adolescents.

Keywords: psychoanalysis; adolescence; social bond; contemporaneity; Facebook.

\section{Resumen}

Este trabajo es resultado de una investigación con el objetivo de analizar la relación entre el uso del Facebook y la formación del lazo social entre adolescentes. Participaron de la investigación 10 adolescentes, que fueron entrevistados, y el principal referencial teórico fue el psicoanálisis. A partir del análisis de los datos, fue posible percibir que la imagen ha ocupado un sitio en los "enlazamientos", 
visto que los adolescentes buscan reconocimiento social por medio de mecanismos del Facebook, valorando aspectos cuantitativos en detrimento de los aspectos cualitativos en las relaciones. Uno de los principales efectos observados fue el debilitamiento de las producciones simbólicas, subjetivas y singulares. Así, el trabajo actúa como punto de partida para futuras discusiones en favor del análisis de las vicisitudes contemporáneas sobre el lazo social establecido por adolescentes.

Palabras clave: psicoanálisis; adolescencia; lazo social; contemporaneidad; Facebook.

\section{Résumé}

Cet article est le résultat d'une recherche qui visait à analyser la relation entre l'utilisation de Facebook et l'établissement du lien social chez les adolescents. Dix adolescents ont participé à la recherche. Ils ont été interviewés, et la psychanalyse a été prise comme cadre théorique principal. À partir de l'analyse des données, il a été possible de percevoir que l'image occupait une place privilégiée dans leurs relations, puisque les adolescents recherchent une reconnaissance sociale à travers des mécanismes de Facebook, en valorisant les aspects quantitatifs au détriment des aspects qualitatifs dans les relations. L'un des principaux effets observés a été l'affaiblissement des productions symboliques, subjectives et singulières. De cette façon, cet article est le point de départ à plusieurs discussions futures en faveur de l'analyse des vicissitudes contemporaines sur le lien social établi par les adolescents.

Mots-clés : psychanalyse ; adolescence ; lien social ; contemporanéité ; Facebook.

Birman, em O sujeito na contemporaneidade (2012), parte do pressuposto de que as transformações culturais e históricas que vêm ocorrendo em todos os níveis sociais incidem na subjetividade produzindo novas formas de mal-estar. As transformações no campo social encontram ressonâncias em elementos psíquicos fundamentais aos modos de subjetivação. Quando buscamos compreender o sujeito e suas diferentes formas de laço social, é de extrema importância analisar o atravessamento histórico-social e suas produções refletidas a partir dos efeitos do mal-estar que cada época produz.

Assim, a contemporaneidade é caracterizada pelo uso de mecanismos que facilitam a interação social, tal como o uso da internet, que, dentro de uma gama de possibilidades, permite que o sujeito altere sua relação com o espaço social em que está inserido. $\mathrm{O}$ atual incremento tecnológico alterou as próprias relações de espaço e tempo (virtualmente, é possível estar em vários locais ao mesmo tempo). Lima (2015) observa que houve um avanço da sociedade em relação à tecnologia, porém, apesar da agilidade, as tarefas multiplicaram-se e o sujeito não se desliga mais dessa ferramenta, que atualmente é possível acessar através dos aparelhos celulares, conferindo a oportunidade de estarem on-line 24 horas por dia. A socialização e o modo de expressão por meio dos mecanismos de comunicação regulados por computadores e celulares são, portanto, uma das principais características da contemporaneidade.

O Facebook é um dispositivo, dentre vários existentes, que a internet nos oferece. Trata-se de uma ferramenta em que o usuário informa o que está fazendo, compartilha fotos em tempo real e é informado sobre aspectos singulares da vida alheia. O Facebook possui cerca de 1 bilhão de usuários, os quais utilizam, em média, 750 minutos por mês os diversos recursos oferecidos por esse site de relacionamentos. No Brasil, esse número já alcança $45 \%$ da população, cerca de 99 milhões de brasileiros possuem uma conta na rede social, o que remete que $8 \mathrm{em}$ cada 10 brasileiros que se conectam à internet possuem uma conta no Facebook. Os números brasileiros são elevados e conferem ao país a terceira posição no ranking mundial de usuários. Entre as particularidades desses números, existe uma participação consistente dos mais jovens, que correspondem a $84,5 \%$ dos usuários brasileiros (Peron, 2016).

Dado tal contexto, quais seriam as possíveis implicações no laço social estabelecido por esses jovens? Para Prioste (2016), existe certo deslocamento do jovem em direção aos contextos sociais e que, somado aos sentimentos ambivalentes diante das figuras parentais, favorecerem a vulnerabilidade dos adolescentes ante os apelos mercadológicos e as promessas idílicas da indústria cultural global na internet. Ainda, para a mesma autora, a insegurança e o desejo de diferenciação dos pais conduzem, por vezes, os adolescentes a buscarem na internet um espaço adequado para obter reconhecimento de seus pares; um espaço no qual possam criar um mundo, viver seus sonhos e negar os limites.

Historicamente, os conceitos de infância e adolescência possuem origem recente na sociedade ocidental, emergidos, mais especificamente, no período moderno. Para Ariès (1978), os conceitos de infância e adolescência que conhecemos hoje são invenções de um tempo histórico e permeados por contingências socioculturais. Por isso, cabe ressaltar que não existe uma infância e uma adolescência, e sim infâncias e adolescências marcadas por diferentes modelagens históricas e culturais. Desse modo, para além das mudanças físicas no âmbito biológico, é importante pensar a adolescência construída a partir de sua historicidade. 
No bojo das produções psicanalíticas, a adolescência se constitui como um período complexo, não somente para o sujeito adolescente, mas também para os adultos. Existe a problemática da existência de desejos ambivalentes de crescer e de regredir, de sentir-se ainda criança ou já adulto, da independência e dependência, da ligação ao passado e projeção para o futuro, assim como maior autonomia em realizar escolhas e a entrada mais efetiva no campo social (Vorcaro, Mazzini, \& Monteiro, 2008).

Pensar tais impasses desse momento da vida requer uma reflexão sobre as características culturais da contemporaneidade para uma melhor compreensão acerca de como as mudanças sociais interferem na constituição do sujeito adolescente e nas manifestações atuais do mal-estar subjetivo. Sendo a adolescência um período marcado por processos identificatórios, Levisky (1998) enfatiza o papel crucial da cultura na constituição subjetiva dos adolescentes, uma vez que a cultura incide sobre os modelos identificatórios dos pais e sobre os próprios adolescentes.

Em decorrência, Vorcaro et al. (2008), assim como Birman (2006), chamam atenção para o quanto a adolescência, período complexo de formação da identidade, pode ser influenciada pelas características consumistas da sociedade capitalista. Sociedade esta que valoriza demonstrações de consumo, capturando também o adolescente na busca de pertencimento por meio da lógica consumista.

Tanto as próprias especificidades da adolescência quanto o contexto social contemporâneo possuem características que a colocam como um período de vulnerabilidade. Não pretendemos negar que a tecnologia tem função importante na nossa sociedade, no entanto cabe questionarmos os possíveis efeitos de tal incremento tecnológico sobre os atuais modos de subjetivação. Com efeito, esta pesquisa visa a analisar de que forma uma importante mídia social - o Facebook - pode atravessar os distintos modos e formatos dos laços sociais estabelecidos por adolescentes na contemporaneidade.

$\mathrm{O}$ estudo pode ser uma possível via para a construção de práticas de atuação que considerem as novas modalidades de laço social dos adolescentes na contemporaneidade. É necessário compreendermos os enlaçamentos por meio da visão e das narrativas dos próprios adolescentes, bem como suas articulações com a dimensão social da contemporaneidade. Portanto, este estudo se justifica perante essas aspirações, se compondo como uma proposta de olhar para esses adolescentes. Concomitante a isso, a utilização da psicanálise auxilia com significativos balizadores para a compreensão dos laços sociais dos adolescentes que fazem uso do Facebook.

\section{Percurso Metodológico}

\section{Tipo de Estudo}

Trata-se de um estudo no campo das ciências humanas em que foi utilizada a entrevista semiestruturada apoiada na análise qualitativa, descritiva e de natureza exploratória. Segundo Turato (2005), a pesquisa qualitativa apresenta interesse em compreender os significados de fenômenos, manifestações, ocorrências, fatos e ideias. Esse modelo de pesquisa não utiliza um instrumento estatístico como base no processo de análise, pois não se pretende enumerar, medir e quantificar os dados. Para além dessas questões, a pesquisa qualitativa com referencial teórico psicanalítico analisa os dados de forma profunda e exclui a possiblidade de recolher os dados com o objetivo de confirmar ou infirmar hipóteses construídas previamente.

O uso da psicanálise como referencial teórico, por sua vez, não se deu em decorrência da mera identificação dos pesquisadores com tal teoria. $\mathrm{O}$ recurso à teoria psicanalítica ocorre por se tratar de uma ciência que se utiliza não apenas do enunciado como instrumento privilegiado, mas também do ato da enunciação. Por sua característica interpretativa, tem o alcance de identificar possíveis tropeços da língua, atos falhos, contradições do discurso e momentos em que o sujeito, ainda que de forma inconsciente, desvela o conteúdo latente de seus atos, modos de sentir e a natureza de seu desejo.

\section{Participantes}

Participaram da pesquisa dez adolescentes, com idade entre 15 e 17 anos, escolhidos de forma randômica, matriculados em um colégio particular de uma cidade do interior de Minas Gerais e cujos pais ou responsáveis consentiram com a participação na pesquisa. O critério para a escolha dos participantes na pesquisa foi determinado pelo fato de que a maioria dos usuários do Facebook é composta por adolescentes, tal como destaca Peron (2016). Além disso, também por se tratar de um período de vulnerabilidade, no qual esses sujeitos estão propensos a inúmeras mudanças nos âmbitos emocionais, comportamentais, sociais e, assim, pela adolescência ser o período que melhor expressa conflitos de uma época.

\section{Instrumento}

Para realização da coleta de dados foi utilizada uma entrevista semiestruturada. Segundo Lüdke e André (1986), a entrevista permite acessar dados de difícil obtenção por meio da observação direta, tais como sentimentos, pensamentos e 
intenções. O propósito da entrevista é fazer com que o entrevistador se coloque dentro da perspectiva do entrevistado, uma vez que outros instrumentos de pesquisa, em geral, estabelecem uma relação hierárquica entre o pesquisador e o pesquisado. $\mathrm{Na}$ entrevista, a relação que se cria é de interação, havendo uma atmosfera de influência recíproca entre quem pergunta e quem responde. A entrevista semiestruturada permite correções, esclarecimentos e adaptações que a tornam eficaz na obtenção das informações desejadas.

A entrevista, em consonância com o método psicanalítico, pode oferecer uma análise aprofundada ao propor desvelar as manifestações inconscientes. Para tanto, Rosa (2004) sinaliza a importância da transferência nesse processo, uma vez que ela se apresenta como instrumento e método não restritos apenas à situação de análise. A escuta psicanalítica é possível, também, em outros contextos para além da clínica, visto que o inconsciente se coloca como determinante de variadas manifestações humanas, culturais e sociais.

\section{Procedimento de Construção e Análise dos Dados}

Foram realizadas dez entrevistas, com duração média de uma hora, individualmente, em uma sala disponibilizada pela coordenação da escola. A escolha por realizar as entrevistas no ambiente escolar dos adolescentes se deu em decorrência da importância de estar inserida no seu ambiente, com o qual já estão habituados, ocasionando uma maior naturalidade ao momento da entrevista. Em relação aos aspectos éticos, o estudo em questão foi aprovado pelo comitê de ética da universidade e foram utilizados nomes fictícios para garantir o sigilo em relação aos participantes. Assim, as entrevistas foram primeiramente áudio-gravadas e depois transcritas na íntegra.

Os registros foram lidos integralmente e estruturados segundo as diretrizes do método de análise de conteúdo, com base no referencial teórico da psicanálise. Segundo Turato (2008), a análise de conteúdo possui fases distintas, que permitem ir além de uma simples descrição, construindo uma análise interpretativa, já que os dados se constituem em "achados mudos", carecendo de análise. O seu início é marcado pela preparação inicial do material, que consiste na sua transcrição. Após essa primeira etapa, a fase de préanálise é marcada por leituras executadas repetidamente. A atenção nesse momento deve incidir nas entrelinhas, naquilo que não foi explicitado na fala. A categorização ocorre a partir de dois critérios: repetição ou relevância. A repetição compreende pontos que se destacam pela frequência com que aparecem, enquanto a relevância diz respeito a um aspecto que, para o pesquisador, é importante por confirmar ou contradizer suas hipóteses (Turato, 2008).

\section{Resultados e Discussão}

As redes sociais, especificamente o Facebook, possuem diversos aparatos que auxiliam os adolescentes de forma positiva. Alguns adolescentes citaram a rede social como um instrumento utilizado para se aproximar de pessoas que estão distantes, servindo como um importante meio de comunicação com característica informativa: "Ele promove essa interação entre pessoas distantes, entre canais comunicativos, eu acho que isso é bem legal, porque deixa a gente muito atualizado sobre as coisas que estão acontecendo" (Matheus, 16 anos). No entanto também pode ser fonte de angústias e sentimentos de não pertencimento social, demonstrado pela incessante busca de reconhecimento através de ferramentas fornecidas pelo próprio Facebook - tal reflexão será aprofundada ao longo da discussão.

O Facebook e outras redes sociais que foram citadas pelos adolescentes no momento da entrevista - como o Instagram, por exemplo - ocupam de maneira quase totalizante o tempo livre desses adolescentes. Os participantes relataram utilizar suas redes sociais nos intervalos das aulas, no horário do almoço, no tempo livre em casa e quando estão com seus amigos. Assim, a partir da análise dos dados, alguns questionamentos surgiram e nortearam as categorias do presente trabalho: como o Facebook pode influenciar os modos de subjetivação e de gestão do mal-estar na contemporaneidade? Quais os efeitos produzidos na regulação dos laços sociais?

\section{O Número como Forma de Reconhecimento Social}

(...) o pessoal pensa sempre assim, que quem tem mais curtida é geralmente a pessoa que é mais legal, que é mais descolada, é popular e, muitas vezes, as pessoas que curtiram nem conhecem a outra pessoa, nem sabem quem é; então eu penso assim, as pessoas levam realmente isso muito a sério, e elas vão buscando maneiras das pessoas curtirem ainda mais as suas fotos (...) pensam que a pessoa que tem mais curtida é a pessoa que tem mais amigos, que é mais popular, mas isso, muitas vezes, não é verdade, porque muitas pessoas, às vezes, curtem para receber curtida de volta e, às vezes, nem sabem quem que é aquela pessoa, o que ela faz, coisas assim. (Beatriz, 17) 
A fala de Beatriz introduz a discussão, pois nela percebe-se o recurso ao exibicionismo enquanto possibilidade de reconhecimento social, que pode ser contabilizado em função do sentimento de pertencimento por meio do número de curtidas. O exibicionismo torna-se uma moeda de troca, pois possibilita receber outras curtidas de volta, destituindo o reconhecimento enquanto gesto espontâneo e o colocando ao nível de valor de mercado. A "curtida" na publicação não é feita pelo reconhecimento de como determinada estética (foto, citação literária, música etc.) afeta a subjetividade, mas, sim, pensada a partir da possibilidade de estar inclusa numa série de trocas. A marca da curtida parece se sobrepor aos gostos pessoais e gestos singulares do sujeito, reduzindo-se a um número a ser contabilizado para garantir o reconhecimento. Gabriel também destaca a questão da importância da contabilização na rede social:

Acho que todo mundo tem aquela sensação de ser reconhecido, de se mostrar, ser popular, quer que todo mundo curta, comente, e a gente também, porque está tudo baseado na mídia. (...) E tem as curtidas, que também está em alta, porque as pessoas ficam até em alta, popular, aí ele vai lá e fala 'aquele ali tem 300 curtidas, vamos ser amigos'. (Gabriel,17)

O que parece aproximar as pessoas está menos ligado à qualidade das relações socialmente estabelecidas do que à quantificação do sujeito por aquilo que ele exibe em sua rede social. Isto, invariavelmente, conduz a pensar que tais modos de relacionamento proporcionam relações objetalizadas, cujo objetivo é ser consumido pelos demais; tanto ao aumentar a quantidade de contatos conquistados, quanto pela quantidade de curtidas nas publicações.

Os depoimentos demonstram existir preocupação quanto à exclusão social, bem como a relação entre a curtida e o afeto. Essa questão é colocada quando Gabriel traz que, se não recebe curtida, instantaneamente tem um pensamento de que ninguém gosta dele: "A gente vai muito pelo grau de fama, de reconhecimento, está muito em alta, e afeta demais a pessoa, porque todo mundo quer ter um reconhecimento, aí meio que se ninguém curtir, a gente pensa que ninguém gosta da gente". Tal condição remete a uma posição em que o sujeito se insere e possui uma característica massificante: precisa estar imerso para ser aceito através de parâmetros pré-estabelecidos de popularidade. Com isso, Herzog e Salztrager (2003) pontuam que, como decorrência da contemporaneidade, há uma forte tendência, por parte de um sujeito eminentemente desamparado, a buscar, a qualquer preço, alguma forma de inclusão no pacto social e que diz, fundamentalmente, sobre a condição narcísica contemporânea, temas a serem tratados mais à frente.

Esses adolescentes demonstram certa dependência e preocupação em se encaixar nos padrões impostos para se sentirem pertencentes ao meio: "É muito difícil você se identificar com o grupo, então a gente tenta ser tudo que dá para ser" (Karina, 16 anos). No que diz respeito ao Facebook, tal condição é reconhecida no instante em que os adolescentes demonstram uma intensa busca daquilo que são, segundo eles mesmos, demonstrações de popularidade, como a quantidade de curtidas. O sujeito torna-se um entusiasta inconteste, obediente a qualquer padrão que é imposto, pressupondo que seus atos e sentimentos não encontram motivação em uma formação desejante singular. Desse modo, ele pode ser facilmente ajustado a determinados padrões e conveniências (Herzog \& Salztrager, 2003).

\section{Confluências entre o Algoritmo e a Clivagem do Eu}

Fortes (2004) chama a atenção para a questão do hedonismo e individualismo na contemporaneidade relacionandoos com o espetáculo, no qual se busca negar o sofrimento, ao passo que a felicidade se torna um imperativo. As mídias sociais e os meios publicitários reforçam essa exigência, colocando a felicidade como um bem que pode ser adquirido "em prateleiras". Faz-se justo destacar que - subjacente à busca de reconhecimento a partir de padrões de consumo - percebeuse o uso de um mecanismo para capturar o sujeito imerso no mundo digital, cujo incremento tecnológico atual permitiu sua difusão pelos mais distintos meios: o algoritmo. Tal mecanismo torna virtualmente possível assinalar hábitos, interesses, padrões de comportamento e outras informações sobre um usuário da rede social e pode ser utilizado para modelar o perfil, bem como para predeterminar possíveis interesses dos usuários da rede.

No caso do Facebook, segundo Jurno e D'Andréa (2015), os algoritmos possuem a função de coordenar as informações exibidas na linha do tempo do perfil de usuário adequando seus desejos ao que será exibido em sua linha do tempo. Os algoritmos são os encarregados por fazer com que o material de maior afinidade à subjetividade do usuário (curtidas, compartilhamentos e imagens) apareça mais vezes em sua linha do tempo. Esses algoritmos funcionam visibilizando ou inviabilizando o aparecimento de postagens, através de uma lógica desconhecida pelos indivíduos.

As variáveis que influenciam ou não o aparecimento de determinados conteúdos no perfil se associam com a frequência de interação que o usuário mantém com certa página ou indivíduo, o número de interações que a postagem tem, a data de publicação, a frequência de interação daquele usuário com aquele tipo de conteúdo, o tempo gasto por aquele sujeito em assuntos daquela mesma temática, entre outros. $\mathrm{O}$ sujeito passa a se relacionar a partir de um espaço constantemente reificado, criando uma espécie de "bolha", cujos conteúdos com os quais irá interagir possuem sempre a mesma temática. 
É possível ofertar no perfil dos usuários uma diversidade de aparatos, tais como mecanismos de recomendação de amigos, conteúdos e indicação de produtos e serviços relacionados aos seus interesses e necessidades. As empresas fazem um bom uso do mecanismo de algoritmo ao buscarem saber mais sobre seus consumidores e, assim, ofertar mercadorias que lhes interessam mais, aumentando o seu lucro (Jurno \& D'Andréa, 2015). Temos aqui um círculo vicioso: quanto mais o sujeito busca pelos seus interesses, mais ele se torna capturado por tais ofertas, mantendo contato apenas com conteúdos já comuns à sua vida.

Trazendo essa discussão para os modos de subjetivação na contemporaneidade, percebemos que a tecnologia em torno do algoritmo se aproxima de um já conhecido mecanismo de estruturação psíquica: a clivagem. Freud (1927/1995), em seu texto sobre o "Fetichismo", assinala que a clivagem corresponde a uma cisão na dinâmica psíquica entre dois modos de funcionamento distintos, bloqueando a relação entre eles. Acredita-se em um aparelho psíquico clivado como sendo um aparato cindido e dissociado, que preserva lado a lado dois dinamismos opostos e heterogêneos que jamais se permutam. A clivagem é definida como resultante de uma cisão no aparelho psíquico em duas faces contrárias: uma que aceita a realidade traumatizante e outra que a nega veementemente. O processo psíquico que desencadeia a clivagem, portanto, é determinado como um ato de rejeição.

A clivagem, enquanto mecanismo de defesa estruturante para o sujeito, encontra no Facebook um mecanismo que opera de forma análoga: o algoritmo. Assim, observa-se um sujeito restringido ao seu universo, sempre repetitivo de consumo, e aos padrões estabelecidos, mas que se dá a partir de um processo ativo, visto que fica posto em jogo um processo de sedução que mobiliza a libido e seu respectivo investimento sobre a dimensão imaginária do laço social. Reforça-se a questão do hedonismo e alienação ao colocar nessa relação dual sempre as mesmas possibilidades de acesso, indo ao encontro do que o sujeito busca: a negação de parte da realidade que lhe seja desagradável e a demonstração de felicidade através de imagens de consumo, pois assim tenta garantir seu reconhecimento.

Os mecanismos contemporâneos, dessa forma, exploram a dimensão imaginária do sujeito. Tal dimensão atinge justamente a questão neurótica: “o que o outro espera de mim?" As falas destacadas ao longo deste trabalho desvelam a submissão dos jovens à busca pela resposta ilusória às demandas do outro, o que nos conduz a uma problemática narcísica contemporânea:

(...) ela [o sujeito refere-se a si em terceira pessoa] se desliga de tudo aquilo, ela vive um teatro praticamente, uma mentira, um personagem, porque ela começa a servir ao próximo e esquece de servir a ela mesma, ela faz a vida dela um fantoche, publica coisas que não representa ela, deixa de fazer coisas que também não representa ela, aí ela começa a seguir uma opinião de tal fulano porque é mais influente, de ciclano porque ele disse que isso é o certo e a gente concordou, e ela vai se abstendo das coisas que ela acredita para tentar atender pedidos das outras pessoas, ela deixa de se aproveitar para atender coisas dos outros, e a maioria das pessoas são assim (...). (Ana, 15)

Para análise mais clara do modo como o narcisismo associa-se com os relatos dos adolescentes, recorre-se às nuances sobre o narcisismo na teoria psicanalítica. As características dessa fase do desenvolvimento são cruciais para as diferentes formas como o sujeito estabelece seus modos futuros de enlaçamento social. Assim, pretende-se tensionar os aspectos envoltos no narcisismo primário e no narcisismo secundário com as implicações sobre os modos de subjetivação no sujeito adolescente.

Na passagem do narcisismo primário para o narcisismo secundário, Freud (1914/1989) descreve que, naquele, a criança é atraída pela imagem do outro e é capturada por essa imagem, definindo uma relação alienante na qual o sujeito percebe o seu desejo neste outro. A montagem do eu ideal é uma consequência da identificação da criança aos primeiros discursos do casal parental. Existe, assim, uma identificação narcísica ao outro primordial, em que o sujeito se encontra encantado pela imagem que ocupa uma posição júbilo. Aponta-se para uma ausência de subjetivação nesse processo, uma vez que não há separação, havendo uma alienação na imagem do outro. É importante salientar que o eu ideal não é uma fase inicial do eu superada e substituída pelo ideal do eu, e que uma vez superado, irá apagar-se (Garcia-Roza, 2002). Embora o retorno ao narcisismo primário se dê por meio da alucinação regressiva, e após a segunda infância o narcisismo seja minimamente secundário, ambas as representações coexistem no inconsciente do indivíduo adulto.

No narcisismo secundário, marcado pela castração, o ideal do eu é construído, principalmente, por exigências externas ao sujeito, regulando as relações entre um eu e um eu ideal. Distintamente do afluxo imaginário que compõe o eu ideal, o ideal do eu corresponde a um conjunto de traços simbólicos constituídos pelo atravessamento da linguagem. A idealização "o que eu gostaria de ser" passa pela escolha objetal de "o que eu preciso ter", o falo. A partir desse movimento, o sujeito organiza sua subjetividade e o simbólico se sobrepõe ao imaginário (Garcia-Roza, 2002). Por meio dos relatos dos adolescentes, percebese que o Facebook atua como mais um de tantos objetos substitutivos ao desejo do sujeito, oferecendo suporte e funcionando de acordo com o ideal do eu: "O Facebook faz com que você conheça alguém e pense "para chegar até ele eu tenho que ser dessa forma', e por isso ficamos tentando chamar atenção da melhor forma que conseguimos.” (Karina, 16 anos).

Albuquerque (2004), ao trazer as formulações acerca do narcisismo para a contemporaneidade, destaca a presença de uma forma primitiva de narcisismo (eu ideal), momento de onipotência e plena satisfação que desvela certa pregnância do 
eu ao ideal cultural. Em um primeiro momento, essa alienação diz respeito a determinadas aspirações, sonhos, valores e idealizações dos pais. É possível conjecturar que esse outro se estabelece na cultura, nas mídias e nos próprios interesses mercadológicos que nos asseguram viver sob um determinado laço social, inclusive no Facebook.

A falta constitutiva do sujeito, a desilusão de onipotência, que, por sua vez, origina outra forma de narcisismo (ideal de $e u$ ), segundo a autora, é encoberta pela oferta de gadgets que proporcionam uma satisfação parcial do sujeito com seu objeto perdido, predominando uma ilusão de completude. Os ideais mercadológicos, ao transformarem o falo em uma mercadoria base do valor de troca social, oferecem diversas formas de satisfação que podem tamponar provisoriamente as lacunas entreabertas pelos ideais a serem conquistados, aumentando consideravelmente o imaginário enquanto registro privilegiado nos modos de estabelecimento do laço social.

Desse modo, como é possível pensar os laços sociais estabelecidos por tais adolescentes na contemporaneidade?

\section{O Laço Social dentro do Facebook: Reflexo da Contemporaneidade}

(...) os amigos do Facebook eu sinto que, querendo ou não, dá uma impressão que é uma competitividade para ver quem parece mais feliz, sabe? É quem vai para tal lugar, é quem frequenta aquela festa, é quem está com tal pessoa, uma procura excessiva de alcançar um status de vida propagando uma informação e publicações por meio da rede social, porque lá eles conseguem uma visualização maior. (Ana, 15)

Fortes (2004) destaca o imperativo de gozo associando-o ao dever de ser feliz na contemporaneidade. Parece haver certa mudança nas formas de subjetivação, uma vez que, tal como apontado por Ana, as relações no Facebook estariam atreladas à competividade acerca de quem se mostra mais feliz. Nesse ponto, a competitividade pode levar ao enfraquecimento dos processos de reconhecimento da alteridade e, consequentemente, à fragilidade dos laços sociais, uma vez que a relação é alicerçada na competição e utiliza-se o outro como recurso para atingir parâmetros de popularidade e pertencimento social:

(...) Os amigos do Facebook eu acho que é até questão de status, "ah eu tenho tantos amigos no Facebook e tal", você não conhece todos eles, você nem sabe quem é a pessoa, então, às vezes, nem conversou com ela, não sabe as atitudes que ela toma, as opiniões que ela tem. (Beatriz, 17)

Dentre as questões formuladas na entrevista, uma delas buscava compreender as diferenças (se houvessem) entre os amigos virtuais e os amigos fora da rede. Ficou evidente que, para a grande maioria, há uma diferença de fato. Quando questionado sobre o número de amigos do Facebook, obtinha-se como resposta média cerca de 2.000 amigos. Em contrapartida, quando questionados sobre a quantidade de amigos fora da rede, a resposta média era em torno de cinco amigos. A internet, dessa forma, como considerou Prioste (2016) em seus estudos sobre as comunidades virtuais, é capaz de propiciar infinitas conexões, porém nem sempre elas são garantia de haver laço social.

Desse modo, faz-se urgente a reflexão sobre o quanto essa realidade, ainda que virtual, caracteriza a subjetividade e denuncia impasses na gestão do mal-estar dos laços sociais cuja solução encontra-se apoiada nas relações de consumo estabelecidas. Para melhor compreensão sobre os laços sociais dos adolescentes nesse contexto, recorre-se à teoria dos discursos, tal como proposto por Lacan (1992). A teoria dos discursos trata de diferentes modos de emparelhamento ou ordenação do gozo por meio da linguagem e auxilia na compreensão das diferentes formas de laço social. Lacan estabelece, a priori, quatro modalidades discursivas: o discurso da histérica, o discurso do universitário, o discurso do analista e o discurso do mestre. Neste trabalho, interessa destacar o discurso do mestre e sua variação, o assim chamado discurso do capitalista, proposto por Lacan (1972). Na figura 1 a estrutura dos discursos indica as posições que se mantêm fixas, sobre as quais os elementos do discurso irão circular.

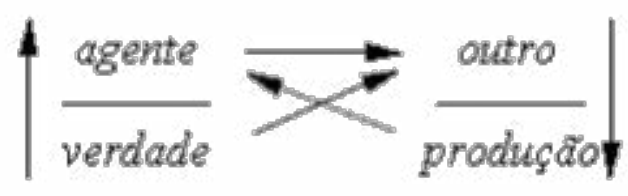

Figura 1. Estrutura dos discursos. 
A figura 2 apresenta o diagrama do discurso do mestre e do capitalista. No discurso do mestre, ou discurso do amo, o significante mestre (S1) é sustentado por uma verdade (\$ - sujeito dividido) e orienta o discurso no lugar do agente, fazendo com que o escravo, representado pelo saber (S2), ocupando o lugar do outro, trabalhe. Assim, o mestre (S1) faz operar o outro, campo estruturado por um saber (S2) em que outros significantes se associam, obtendo como produto o objeto $a$, certo resto que não toca a verdade do sujeito (\$), qual seja, sua condição castrada. Nesse trajeto, há uma perda, um produto final denominado objeto $a$ ou mais-de-gozar. Esse produto, oriundo da perda de gozo, se faz essencial para a entrada do sujeito na linguagem, tornando-se um ser falante, castrado de uma parcela de seu gozo, sendo essa perda sinalizada pelo objeto $a$. Nesse processo, há a exclusão da fantasia $(\$<>a)$ interditando a apropriação pelo sujeito de seu produto, excedente de gozo, representado pela impotência (//) (Lacan, 1992).

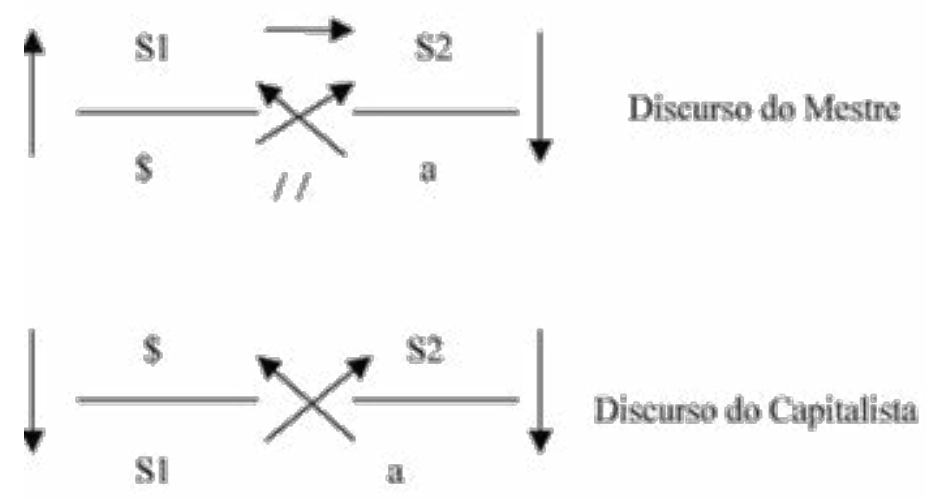

Figura 2. Discurso do mestre e discurso do capitalista.

Enquanto variante do discurso do mestre, Lacan (1972), na Conferência de Milão, propõe a montagem do assim denominado discurso do capitalista. Neste, há uma troca de posição do mestre (S1), que agora é localizado no lugar da verdade, invertendo sua posição com o sujeito (\$), que toma as rédeas enquanto agente do discurso, numa relação direta com a verdade, em que esta passa a ser alimentada. Aqui, não existe a dupla barra da impotência para fazer o impedimento de acesso ao gozo através do objeto causa do desejo. Porém, apesar de existir uma relação do objeto $a$ que está no lugar da produção direta com o sujeito (\$), não há relação entre o agente e o outro (entre \$ e S2), levando à reflexão sobre o laço social no discurso do capitalista.

A possibilidade de relação com o objeto causa do desejo se associa com a falta da barra que liga o sujeito ao mais-degozar. Como isso se reflete no sujeito? Quinet (2009) aponta a incidência de um sujeito reduzido à posição de consumidor de objetos produzidos pelo capitalismo na busca por alcançar o seu objeto perdido. Em suma, há uma oferta de objetos para suprir a falta no sujeito, esses objetos - denominados por Lacan (1972) como gadgets - são objetos descartáveis que fornecem uma satisfação irrisória ao sujeito. Retomando a questão do laço social: se a condição do laço se relaciona com o sujeito restar castrado e tomar o outro como suporte - cabendo à fantasia o tratamento da realidade -, no discurso do capitalista há uma predominância da relação do sujeito com os objetos fornecidos pelo mercado como promessa de satisfação e completude. Cabe, portanto, o seguinte questionamento: como se dá a relação entre os pares nesse contexto?

Para Quinet (2009), o consumismo atingiu níveis tão altos que o próprio sujeito também se coloca como uma mercadoria, como algo a ser usado e descartado. Nesse sentido, não é somente com os objetos que há uma relação de consumo, mas também entre os próprios sujeitos. No mundo digital, a partir dos depoimentos dos adolescentes, percebese certa desvalorização das relações afetivas e uma sobrevalorização das relações pautadas pelo universo das quantidades (número de curtidas e amigos), apontando o alargamento do campo imaginário. O sujeito torna-se, ele mesmo, um bem capitalizável a ser consumido. A satisfação se dá quando ele passa a ser reconhecido enquanto quantificador de atrativos, utilizando o outro, e se colocando como gadget, para se assegurar do pacto social.

Ao promover o consumo de modo ininterrupto, com a supressão da impotência representada pela barreira de gozo (//), Quinet (2009) chama atenção para o efeito de tal movimento sobre a castração: sua foraclusão. Tal condição, própria ao discurso do capitalista, é demonstrada na relação com os objetos e na ausência da relação do sujeito com o outro a partir da exclusão da relação permeada pela fantasia $(\$<>a)$. O plano simbólico se torna fragilizado, e demonstra-se a possível ilusão de extinção da falta ao colocar à disposição de seus sujeitos objetos aos quais se confere o poder de suceder imediatamente, mas ainda provisoriamente e ilusoriamente, o desejo. 
Essa problemática transposta para a subjetivação do adolescente traz questionamentos importantes a serem analisados em estudos posteriores, uma vez que a adolescência se caracteriza pela predominância dos processos identificatórios na constituição do sujeito, na passagem do mundo infantil para o mundo adulto. Nesse momento, para além das relações parentais, o adolescente busca reformular suas identificações no meio social construindo novos objetos pulsionais (Gomes \& Caniato, 2016).

$\mathrm{Na}$ análise sobre os modos de enlaçamento social do adolescente no Facebook, percebemos que as identificações ocupam um lugar precário, ao passo em que a relação é estabelecida por meio da competitividade no mundo virtual e da utilização de procedimentos quantificatórios do outro como gratificação parcial ante a falta estruturante. Os elementos que compõem a conjuntura social e cultural da contemporaneidade, como os algoritmos e as propostas mercadológicas, também atravessam os adolescentes em suas relações, incidindo marcas em sua constituição subjetiva.

\section{Considerações Finais}

Tomando a discussão apresentada neste trabalho, percebeu-se que as redes sociais -especificamente o Facebook - são reflexos de um adolescente que busca atender ao reconhecimento do outro, estabelecido nas vicissitudes contemporâneas e na ideologia mercadológica que permeia o modelo capitalista. Demonstrou-se o quanto os parâmetros de popularidade espetacularizados podem modificar a vivência singular de sua própria subjetividade. Assim, entende-se que o uso do Facebook fornece suporte para a reflexão sobre os modos de enlaçamento social na contemporaneidade.

Não cabem generalizações para essa problemática, haja vista que a psicanálise não possui caráter de completo saber da verdade e que é reconhecido que cada um possui o seu próprio modo de utilizar a rede social. Sinalizamos o que foi encontrado durante o processo de análise, que se trata de uma mudança em alguns tradicionais modos de produções simbólicas, subjetivas e singulares que possuem, pela dimensão da alteridade, seu modo de regulação social. O estudo apontou também que tais alterações satisfazem os ideais capitalistas, visto que, ao disseminar padrões e capturar o sujeito através do algoritmo nas redes, tem-se um consumismo ainda mais intensificado, gerando lucro.

Destaca-se, ainda, o quanto a psicanálise é capaz de enriquecer o conhecimento acerca do campo social. A análise aqui apresentada pode ser uma possível via para a construção de práticas de atuação que reconheçam esse novo campo discursivo, figurativo, normativo e técnico. É necessário olhar para o sujeito que se desvela diante da fragilidade simbólica percebida no contemporâneo, tal como observado nesta pesquisa. Afinal, a psicanálise está voltada para a produção de novos sentidos a partir da singularidade do sujeito.

Por fim, não há a pretensão de findar a discussão em torno das relações sociais dos adolescentes na contemporaneidade, de modo que os apontamentos apresentados possuam um caráter absoluto. Sabemos que o trabalho se moldou por uma questão inicial causadora de diversas outras inquietações, de modo que, com efeito, aponta-se um rico ponto de partida para futuras discussões.

\section{Referências}

Albuquerque, A. (2004). O sofrimento na cultura atual: Hedonismo versus alteridade. In C. A. Peixoto Jr. (Org.), Formas de subjetivação (pp. 95-114). Rio de Janeiro: Contra Capa.

Ariès, P. (1978). A história social da criança e da família. Rio de Janeiro: Guanabara.

Birman, J. (2006). Tatuando o desamparo: A juventude na atualidade. In M. R. Cardoso (Org.), Adolescentes (pp. 25-43). Rio de Janeiro: Escuta.

Birman, J. (2012). O sujeito na contemporaneidade. Rio de Janeiro: Civilização Brasileira.

Fortes, I. (2004). O sofrimento na cultura na cultura atual: Hedonismo versus alteridade. In C. A. Peixoto Jr. (Org.), Formas de subjetivação (pp. 69-94). Rio de Janeiro: Contra Capa.

Freud, S. (1989). Sobre o narcisismo: Uma introdução. Edição Standard das Obras Psicológicas Completas de Sigmund Freud, vol. 14. Rio de Janeiro: Imago Editora. (Originalmente publicado em 1914)

Freud, S. (1995). Fetichismo. Edição Standard Brasileira das Obras Psicológicas Completas de Sigmund Freud, vol. 21. Rio de Janeiro: Imago Editora. (Originalmente publicado em 1927) 
Garcia-Roza, L. A. (2002). Introdução à metapsicologia freudiana 3 - Artigos de metapsicologia, 1914-1917: Narcisismo, pulsão, recalque, inconsciente. Rio de Janeiro: Jorge Zahar.

Gomes, V. R. R., \& Caniato, A. (2016). Adolescentes na contemporaneidade: Desdobramentos subjetivos do (des) investimento no virtual. Contextos Clínicos, 1(9), 133-146.

Herzog, R., \& Salztrager, R. (2003). A formação de identidade na sociedade contemporânea. In T. Pinheiro (Org.), Psicanálise e formas de subjetivação contemporâneas (pp. 27-42). Rio de Janeiro: Contra Capa.

Jurno, A. C., \& D'Andréa, C. F. B. (2015). Agenciamentos e redes textuais no Facebook: uma cartografia do "feed de notícias". In Anais do XXXVIII Congresso Brasileiro de Ciências da Comunicação, 4 (pp. 1-15). Rio de Janeiro: Universidade Federal do Rio de Janeiro.

Lacan, J. (1972). Discours de Jacques Lacan à l’Université de Milan. Lacan in Italia (pp. 32-55). Milan, LOM.

Lacan, J. (1992). O seminário: livro 17 - O avesso da psicanálise (1969-1970). Rio de Janeiro: Jorge Zahar.

Levisky, D. L. (1998). Adolescência: Reflexões psicanalíticas. São Paulo, Casa do Psicólogo.

Lima, L. V. (2015). Os mendigos de likes. Dissertação de Mestrado, Instituto de Psicologia, Universidade Federal de Uberlândia, Uberlândia.

Lüdke, M., \& André, M. (1986). Pesquisa em educação: Abordagens qualitativas. São Paulo: Editora Pedagógica e Universitária.

Peron, A. (2016). Facebook marketing: Dados de 2016 da maior rede social do mundo. Link

Prioste, C. (2016). O adolescente e a internet. Laços e embaraços no mundo virtual. São Paulo: EDUSP.

Quinet, A. (2009). Psicose e laço social: Esquizofrenia, paranóia e melancolia. Rio de Janeiro: Jorge Zahar.

Rosa, M. D. (2004). A pesquisa psicanalítica dos fenômenos sociais e políticos: Metodologia e fundamentação teórica. Revista Mal-Estar e Subjetividade, 4(2), 329-348.

Turato, E. R. (2005). Métodos qualitativos e quantitativos na área da saúde: definições, diferenças e seus objetos de pesquisa. Revista de Saúde Pública, 39(3), 507-514. DOI: 10.1590/S0034-89102005000300025

Turato, E. R. (2008). Tratando e discutindo os dados para a contribuição do pesquisador ao repensar do conhecimento científico. In E. R. Turato (Org.), Tratado da metodologia de pesquisa clínico-qualitativa: Construção teóricaepistemológica, discussão comparada e aplicação nas áreas de saúde e humanas (pp. 437-465). Petrópolis, RJ: Vozes.

Vorcaro, A., Mazzini, C. A., \& Monteiro, J. P. (2008). Ato infracional e metáfora paterna. Psicologia: Teoria e Prática, 10(2), 135-146. 


\section{Como citar:}

Lima, L. M., \& Rocha, T. H. R. (2020). Adolescência e Laço Social: Uma Leitura Psicanalítica sobre o Uso do Facebook. Revista Subjetividades, 20(Esp 2. O Contemporâneo à Luz da Psicanálise), e9498. http://doi.org/10.5020/23590777. rs.v20iEsp2.e9498

\section{Endereço para correspondência}

Lívia de Matos Lima

E-mail: livia_matos1@hotmail.com

Tiago Humberto Rodrigues Rocha

E-mail: tiagohrr@hotmail.com 